\title{
Morphology and texture of co-evaporated Co-Cr films
}

\author{
Herma van Kranenburg, Cock Lodder and Theo J.A. Popma \\ Mesa Research Institute, University of Twente, P.O. Box 217, 7500 AE Enschede, The Netherlands
}

\begin{abstract}
The microstructure of co-evaporated $\mathrm{Co}-\mathrm{Cr}$ films is investigated. The columnar morphology is tilted towards the main source. Due to the geometry effect of opposing vapour directions, compositional separation occurs. With AES direct proof of this was established. Consequently it is unnecessary to increase the substrate temperature to obtain enhanced energy products.
\end{abstract}

\section{Introduction}

Co-evaporated $\mathrm{Co}-\mathrm{Cr}$ films were deposited with two e-beam sources and under oblique opposing vapour directions, as described in ref. [1]. The two incidence angles were equal (symmetric deposition geometry): $\alpha_{i, \mathrm{Co}}=\alpha_{\mathrm{i}, \mathrm{Cr}}=25-30^{\circ}$. Besides these films on Si substrates, we deposited films on $12.5 \mu \mathrm{m}$ thick polyimide with the same evaporation geometry. In this paper we use code names starting with either an F for films on polyimide or $\mathrm{M}$ for those on Si substrates. The F-samples were deposited at room temperature. The average $\mathrm{Cr}$ content is about 25 at\%. The $\mathrm{M}$ samples were deposited at either room temperature $\left(T_{\mathrm{R}}\right)$ or higher $\left(T_{\mathrm{H}}\right)$ [1]. In order to obtain comparable saturation magnetizations, the $T_{\mathrm{H}}$ samples were made with higher average $\mathrm{Cr}$ contents of approximately 28 at $\%$. The $\mathrm{Si}$ substrates were cleaned with 2-propanol prior to deposition, whereas the polyimide was given no pre-treatment.

The magnetic properties were characterized by VSM and torque measurements. The average $\mathrm{Cr}$ content was measured by XRF. The microstructure was investigated with TEM, XRD and AES. With X-ray diffraction (XRD), $\theta-2 \theta$ scans were made to determine the phase configuration and the texture was measured. The lattice spacing of the $\mathrm{Co}-\mathrm{Cr}$ films was compared with that of obliquely evaporated pure Co (and pure $\mathrm{Cr}$ ) films. Cross-sectional studies of the samples on $\mathrm{Si}$ were made with TEM. These observations supplied additional information for our earlier SEM investigations [1]. AES depth profiling was used to determine the ratio of oxygen, $\mathrm{Cr}$ and $\mathrm{Co}$ throughout the whole

Correspondence to: Dr. J.C. Lodder, Mesa Research Institute, University of Twente, P.O. Box 217, 7500 AE Enschede, the Netherlands. Tel.: +31-53-892750, telefax: +31-53-309547; telex 44200; e-mail: LODDER@UTWENTE. NL. film thickness. In addition to the Co-Cr films a pure $\mathrm{Co}$ and a pure $\mathrm{Cr}$ film were also analyzed. For the sputter etching a beam of $\mathrm{Ar}^{+}$ions was used with an energy of $3.5 \mathrm{keV}$ and a current of $2.5 \mathrm{~mA}$ for the top layer and $25 \mathrm{~mA}$ for the remaining part of the film. The probing beam had an energy of $3 \mathrm{keV}$ and a current of $0.1 \mu \mathrm{A}$. For the detection limits we estimated for a S/N ratio of 10: 2.0 at $\% \mathrm{Cr}, 2.4$ at\% Co and 1.3 at $\% \mathrm{O}$. For direct proof of the process-induced compositional separation we performed Auger point measurements on two sides of a fractured $T_{\mathrm{R}}$ sample. In this experiment no sputter etching was applied and the probing electron beam had an energy of $10 \mathrm{keV}$ and a current of $1.9 \mathrm{nA}$. The $\mathrm{Co}, \mathrm{Cr}$ and $\mathrm{O}$ Auger signals of areas of approximately $400 \mathrm{~nm}$ in diameter were averaged. The estimated information depth in this experiment was $10 \AA$.

\section{Results}

The magnetic properties of the films on $\mathrm{Si}$ have been discussed in ref. [1]. Numerical magnetic data for a selection of samples are given in table 1 , where we present films of various thicknesses with $M_{\mathrm{s}}$ of around $455 \mathrm{kA} / \mathrm{m}$. These saturation magnetizations were reached with very high $\mathrm{Cr}$ contents. The perpendicular coercivities were also enhanced at room-temperature evaporation. This is a result of compositional separation caused by the opposing directions of the (ferromagnetic) $\mathrm{Co}$ and (non-ferromagnetic) $\mathrm{Cr}$ vapour beams [1] (see also fig. 3); we therefore call this separation 'process-induced compositional separation'. Our coevaporated $\mathrm{Co}-\mathrm{Cr}$ films deposited on polyimide show the same magnetic characteristics as those on $\mathrm{Si}$ substrates. With 25 at $\% \mathrm{Cr}, M_{\mathrm{s}}$ is around $465 \mathrm{kA} / \mathrm{m}$ and $H_{\mathrm{c} \perp}$ around $60 \mathrm{kA} / \mathrm{m}$; see table $1 . K_{1}$, a combination of hcp crystalline anisotropy and columnar shape anisotropy, is around $160 \mathrm{~kJ} \mathrm{~m}^{-3}$, and is tilted by $7^{\circ}$ with respect to the film normal. The transversal 
Table 1

Magnetic properties of selected samples

\begin{tabular}{llllllll}
\hline Film & $\begin{array}{l}h \\
{[\mathrm{~nm}]}\end{array}$ & $\begin{array}{l}\text { at\% } \\
\mathrm{Cr}\end{array}$ & $\begin{array}{l}M_{\mathrm{s}} \\
{[\mathrm{kA} / \mathrm{m}]}\end{array}$ & $\begin{array}{l}H_{\mathrm{c} \perp} \\
\mathrm{LM} \\
{[\mathrm{kA} / \mathrm{m}]}\end{array}$ & $\begin{array}{l}H_{\mathrm{c} \|} \\
\mathrm{LM} \\
{[\mathrm{kA} / \mathrm{m}]}\end{array}$ & $\begin{array}{l}K_{1} \\
{\left[\mathrm{~kJ} \mathrm{~m}^{-3}\right]}\end{array}$ & $\begin{array}{l}K_{\mathrm{t}} \\
{\left[\mathrm{kJ} \mathrm{m}^{-3}\right]}\end{array}$ \\
\hline M16 & 84 & 23.6 & 446 & 54 & 28 & 95 & 19 \\
M11 & 231 & 24.1 & 465 & 59 & 27 & 135 & 30 \\
M12 $_{\text {M19 }}^{\text {a) }}$ & 356 & 24.7 & 471 & 57 & 31 & 140 & 35 \\
M18 $^{\text {a) }}$ & 262 & 29.1 & 446 & 115 & 30 & 141 & 28 \\
F20 & 399 & 27.6 & 457 & 91 & 33 & 137 & 31 \\
F21 & 330 & 24.9 & 474 & 59 & 28 & 161 & 26 \\
\hline
\end{tabular}

a) Samples M18 and M19 were deposited at elevated temperature $\left(T_{\mathrm{H}}\right)$; all others at room temperature $\left(T_{\mathrm{R}}\right)$.

anisotropy constant $K_{\mathrm{t}}$ is approximately $26 \mathrm{~kJ} \mathrm{~m}^{-3}$; see table 1 . The films have some tensile stress.

The morphology is columnar and tilted towards the main source $(=\mathrm{Co})$ direction. The structure was hcp. In fig. 1, TEM bright-field images (BFI) of M16 are given. The cross section is parallel to the evaporation plane. The tilted columns can clearly be observed. Their tilt angle of about $14^{\circ}$ with respect to the film normal, is consistent with growth models [2,3]. The columnar size was $7.5-15 \mathrm{~nm}$. In the enlargement in the inset of fig. 1 defects are visible. These are thought to be stacking faults lying on the (0001) planes [4]. There seem to be more stacking faults in the $T_{\mathrm{H}}$ samples. A large number of them can be seen in the dark-field image of M18 in fig. 2. The columns are larger in the $T_{\mathrm{H}}$ samples; in the case of M18 we measured 20-25 $\mathrm{nm}$. The stacking faults are believed to arise from the fact that a perpendicular $c$-axis is energetically favourable, while oblique-incidence deposition results in a tilted columnar morphology, making it more difficult for the perpendicular $c$-axis orientation to develop. The defects offer a possibility to relieve the stress that thus arises. The columnar tilt angle decreases with deposition temperature. For the $T_{\mathrm{R}}$ samples we typically measured $7-8^{\circ}$, compared with $12-15^{\circ}$ for the $T_{\mathrm{R}}$ samples. This is a result of the higher adatom mobility, which partly annuls the shadowing effect, which in turn causes the inclined columns. The $c$-axis of the hep structure is inclined towards the Co source direction. For the $T_{\mathrm{R}}$ samples we measured (with XRD) a larger $c$-axis tilt angle and a smaller lattice spacing than for the $T_{\mathrm{H}}$ samples. Typical values for the $c$-axis tilt were $5-9^{\circ}\left(T_{\mathrm{R}}\right)$ and $0-5^{\circ}\left(T_{\mathrm{H}}\right)$. Lattice data for the $T_{\mathrm{R}}$ samples were $d_{(0002)}=2.028-$ $2.029 \AA, a=2.494 \AA$ and $c / a=1.626$, and for the $T_{\mathrm{H}}$ samples $d_{(0002)}=2.033 \AA, a=2.502 \AA$ and $c / a=1.625$. For comparison, we obliquely evaporated pure $C o$ and pure $\mathrm{Cr}$ films at room temperature. The structure of the Co film was hcp ( $c$-axis tilt $4^{\circ}$ with respect to film normal) possibly with coexisting fcc. The lattice spacing of the (0002) planes was larger than that of the ASTM index, but very close to the high temperature samples. We measured $d_{(0002)}=2.035 \AA, a=2.494 \AA$ and $c / a$ $=1.632$. The structure of the $\mathrm{Cr}$ film was cubic with the (110) planes parallel to the substrate and $d_{(110)}=$ $2.034 \AA$.

With AES we measured depth profiles. A very large amount of oxygen was found in all films, in a relatively thick layer at the surface. The open regions between the columns (that arise due to shadowed areas and limited adatom mobility) enable the 'oxygen layer' to become thicker than in dense structures. The oxygen-

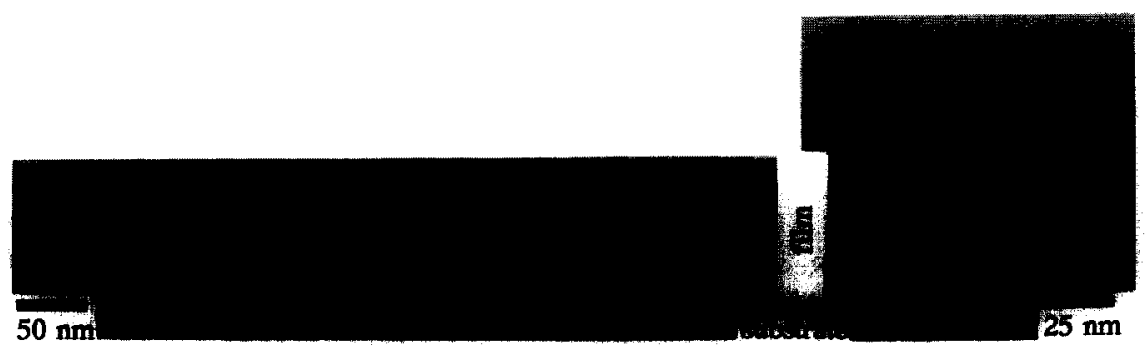

Fig. 1. TEM cross-sections parallel to the evaporation plane (BFI) of M16, with an enlargement inset. 


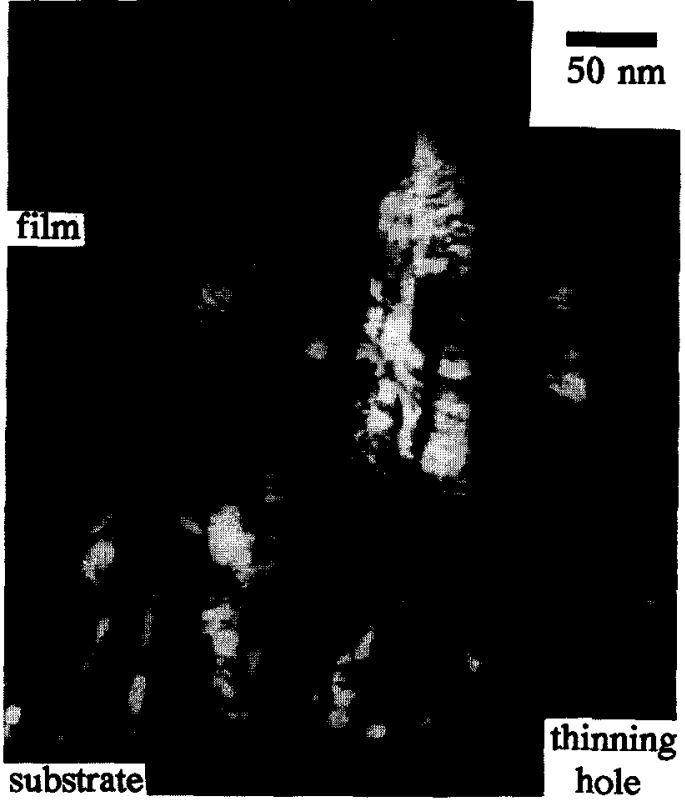

Fig. 2. TEM cross-section parallel to the evaporation plane (dark-field image) of M18.

containing layer thickness increased with film thickness and decreased with deposition temperature. Further the oxygen content was lower in the $T_{H}$ samples, presumably because of the higher density of the $T_{\mathrm{H}}$ films. For the films listed in table 1 the quotients of the thicknesses of layers containing oxygen and the total layer thickness were: 50\% (M16), 53\% (M11), 64\% (M12), 28\% (M19) and 35\% (M18). In sputtered $\mathrm{Co}-\mathrm{Cr}$ films [5], for example a quotient of only $6 \%$ or less was measured.

In another Auger experiment a fractured room-temperature sample (M12) was observed in a plane perpendicular to the evaporation plane (see fig. 3). On both (as-broken) surfaces the $\mathrm{Co}, \mathrm{Cr}$ and $\mathrm{O}$ Auger signals were measured. On one surface (A) a clear $\mathrm{Cr}$ signal was measured, while on the other surface (B) only a slight signal was detected, as can be seen in fig. 3. Further the Co signal was weaker on surface $A$ than on surface B. Thus the indirect proof of the existence of the process-induced compositional separation was provided by measurements of the enhanced energy product [1], NMR [6] and simulations of film growth [3], we can now add this direct proof established with AES. It is thus concluded that compositional separation can be induced by two opposing directions of ferro- and non-ferromagnetic vapour.

We acknowledge the assistance of Dr. E.G. Keim and A.H.J. van den Berg in the Auger experiments and Dr. L. Toth in the TEM observations. Discussions with Dr. Y. Sakamoto from Matsushita Electric Industrial Co. are greatly appreciated.

\section{References}

[1] H. van Kranenburg, J.C. Lodder, Th.J.A. Popma, K. Takei and Y. Maeda, J. Magn. Soc. Jpn. 15 Suppl. \$2 (1991) 33.
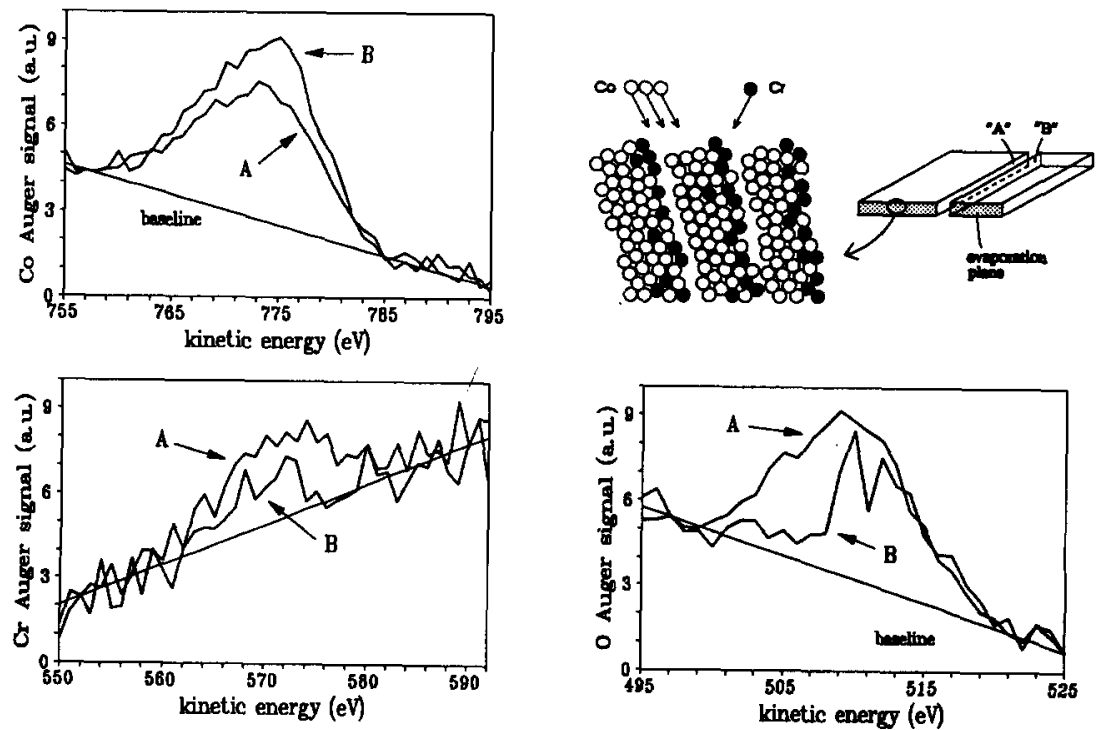

Fig. 3. $\mathrm{Co}, \mathrm{Cr}$ and $\mathrm{O}$ Auger signals measured on the $\mathrm{Cr}$-rich (A) and Co-rich (B) surfaces in sample M12. 
[2] A.G. Dirks and H.J. Leamy, Thin Solid Films 47 (1977) 219.

[3] S. Müller-Pfeiffer, H. van Kranenburg and J.C. Lodder, Thin Solid Films 213 (1992) 143.

[4] K. Hono, B.G. Demczyk and D.E. Laughlin, Appl. Phys. Lett. 55 (1989) 229.
[5] T. Masuda, W. Geerts and J.C. Lodder, J. Magn. Magn. Mater. 95 (1991) 123.

[6] J.C. Lodder, H. van Kranenburg, K. Takei and Y. Maeda, J. Magn. Magn. Mater, to be published. 